\title{
Revolutionary Objects: Pure Forms and Disorder in Ivan Leonidov's Work
}

\author{
François Blanciak \\ Faculty of Architecture, Design and Planning, University of Sydney, NSW 2006, Australia
}

\begin{abstract}
This paper analyzes compositional strategies of Russian avant-garde architecture from the 1920s and 1930s through the study of the work of Ivan Leonidov (1902-1959), one of the leading and most prolific architects of this movement. In this study, Leonidov's work is located within its predominant architectural context, and his work is interpreted not only as a reaction against the domineering principles of classicism, but as an evolution and selective continuation of key concepts directly translated from architectural academism. The issues of the use of pure forms - a radical stance at odds with the commonly accepted morphologies of that era - associated with the principles of displaced symmetry, or disorder, are closely looked at and evaluated against both their architectural and political values within the context of post-revolutionary Russia. It is argued that the characteristic of weightlessness in his large-scale planning proposals is revelatory of a particular desire to invade space with political presence, thus demanding to reconsider the relation between space and architectural objects. Parallels are also drawn from French Revolutionary architecture, and from the work of Claude-Nicolas Ledoux in particular, whose search for purity and autonomy in architectural morphology preceded that of Soviet architecture. As Leonidov's legacy mainly consists of drawings of buildings that never got built, his influence can often be felt in the work of other architects which until today have drawn formal elements and compositional strategies from his relatively vast volume of un-built work.
\end{abstract}

Key words: Ivan Leonidov, constructivism, design theory.

\section{Introduction}

This paper aims to analyze compositional strategies of Russian avant-garde architecture from the 1920s and 1930s through the study of the work of Ivan Leonidov (1902-1959), one of the leading and most prolific architects of this movement. The study aims to interpret his work not only as a reaction against the domineering principles of classicism, but as an evolution and selective continuation of key concepts directly translated from architectural academism. Analyzing the influence of classicism on Leonidov deserves attention, as it has so far been studied only in relation to his later designs [1], which do not reflect his actual contribution to architecture, or in relation to eighteenth century French Revolutionary architecture, with a focus on similarity rather than difference [2].

Corresponding author: François Blanciak, Ph.D., lecturer, research fields: architecture and design theory. E-mail: francois.blanciak@sydney.edu.au.
Following a presentation of the specific context within which Leonidov operated, a second part will attempt to identify the specific nature of his formal vocabulary through their adaptation (and resistance) to various contexts and programs. What will be focused on, hence, are the organizational principles that governed the compositions which he made from the most basic set of forms.

\section{Context}

In order to understand the meaning of Constructivism, one has to understand the predominant architectural context out of which it emerged. Constructivism is, in the broader sense, an artistic movement started in the wake of the Soviet Revolution of 1917, which aimed to use art as an instrument for the construction of a socialist system. In early twentieth century Russia, neoclassicism was the domineering architectural trend, exemplified by 
buildings designed by architects such as Ivan Fomin. These building designs relied heavily on the Doric order, as the simplest order to be able to represent the crude aspirations of the proletariat, which led to the creation of a style called "Red Doric" in the early post-revolutionary period.

The rise of constructivism succeeds to this period. The 1920s also became the scene for a drastic expansion of the territory of the USSR (Union of Soviet Socialist Republics). On December 1922, a conference of delegations from Russia, the Transcaucasian SSR, Ukraine and Byelorussia approved a treaty of creation of the Union of Soviet Socialist Republics. In addition, a growing rivalry with the United States of America, then still dominated by the Beaux-Arts aesthetics, ran parallel to this quest for a revolutionary architecture.

The outcome of this era, in Russian architecture, was a rejection of classicist principles. However, as Kahn-Magomedov pointed out: "The outstanding feature of the new developments in Soviet architecture during the 1920s was an explicit negation of the pre-Revolutionary Moderne (Art Nouveau). This rejection was even more categorical than the rejection of classicism, since almost every one of the supporters of the new architecture had undertaken a thorough study of the latter trend, if only during the years immediately following the Revolution [3].”

It is within this context that Ivan Leonidov intervenes in the course of modern Russian architecture, within the second phase of constructivism. Unlike many famous architects, his social and cultural backgrounds were far from destining him to become a leading practitioner. It is worth noting that politics can be viewed as a decisive cause in both the rise and fall of Leonidov as an icon of constructivism [4].

\section{Principles of Composition}

\subsection{Classical Composition}

Composition in architectural design refers mainly to the techniques of planning. It consists in the arrangement of the different elements of a project in a given settlement according to artistic principles. The primary aims of composition are to contribute to a gratifying response from the viewer, due to the perception of the work as being aesthetic, through the selection and appropriate placement of elements within the work. John Summerson, in "The Classical Language of Architecture", has described how classical architecture, its Renaissance revival, as well as Baroque architecture have all based their compositional dogma on symmetry, cohesiveness and groundedness [5].

Early modern reactions against architectural dogma based on axiality inherited from the neoclassical and baroque eras can be sensed in Le Corbusier's “Towards a New Architecture" of 1923, in which he praises the arrangement of the Acropolis in Athens in plan: "Because they are out of this single axis, the Parthenon on the right and the Erechtheion on the left, one has the chance to see them from the side, in their entire physiognomy. One should not set all the things of architecture on axes, because they would turn into as many people speaking at the same time [6]". Le Corbusier's prose reveals both the knowledge and respect of ancient composition rules by early modernists, and their intentions to reinterpret them through modern designs.

\subsection{Case Study: A Club of a New Social Type, Moscow (1928)}

As a project that embodies clearly most of the compositional strategies defined by Leonidov and their relation to the notion of social re-organization, his proposal for a club of a new social type is hereby cinematically decomposed and recomposed in order to understand the mechanisms at stake. Adhering to the principle of programmatic invention, the complex was designed to accommodate spaces for various cultural amenities (such as museums, planetarium, etc.), sports facilities, political gathering areas, as well as spaces 
for military exercise.

In Leonidov's vision, the club's analytical and mass work would be supervised by trained teachers gathered in a central institute communicating by radio. Daily economic and political news, as well as club and scientific institute activities, would be broadcasted on screens, or reported over loudspeakers, to ensure high quality instruction and the widest possible diffusion. When asked a question regarding the use of identical forms for different functions at a lecture in which he presented this scheme in 1928, Leonidov contested the view that he was primarily interested in external form: "It is not the form one should consider and criticize, but the methods of cultural organization [7]". While some particular aesthetic sense might first strike in his projects, Leonidov in fact construed his design principles around a rationale which intended to relate to the construction of the USSR as a condenser for new social relationships.

From a compositional point of view, one might observe that the building program is broken into a series of simple geometrical shapes, which all have at least two axes of symmetry each, but that these axes do not coincide with each other, which creates a dynamic composition. Fig. 1 proposes to recompose this project in plan from a point where all figures share the same center. The very first drawing of this

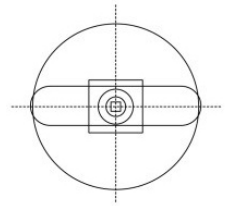

1.

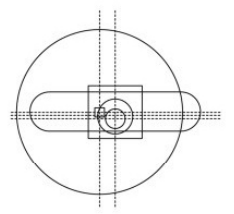

4.

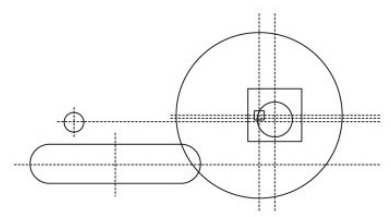

7.

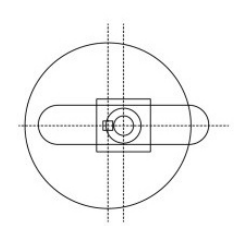

2.

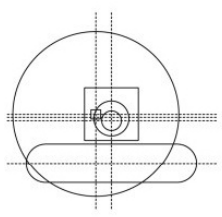

5.

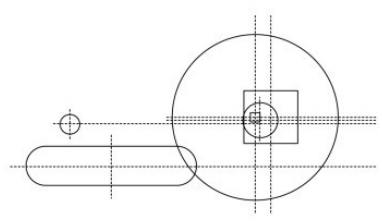

8

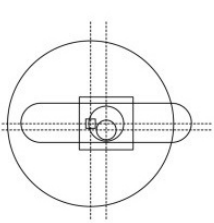

3.

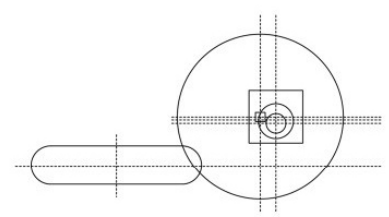

6.

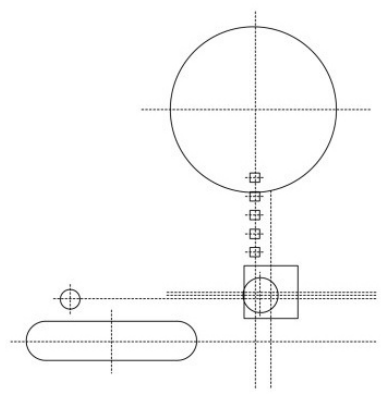

9

Fig. 1 Theoretical recomposition of Ivan Leonidov's design for a club of a new social type (1928) from a classicist basis in plan. 
series thus corresponds to a classical type of architectural composition. Form this common standpoint, one can observe two phases in the recomposition process. In the first phase (observable in drawing 1 to 5), the orthogonal axes of symmetry of the various building elements of the project are simply dislocated from each other so as to avoid the notion of center. This is made clear by the multiplication of symmetry axes in plan, while in the second phase (from drawing 6 to 9), the building elements are virtually ejected from the former center through a movement of translation along their respective dislocated axis of symmetry in a spiraling way, as if weightless.

This graphic theoretical method of recomposing the project is used to show at once the classical origin of the composition, and the way this latter distinguishes itself from classical principles. The same sequence of movements would be observable if a different center was chosen as the origin of the composition. The effect of disorder in composition becomes intelligible through this analytical method: not only the classicist origins of constructivist planning principles become clear, but also the way they depart from that root. In addition, this method of representation of the building process as a compositional sequence allows one to identify the concept of dynamic composition, as one that is the result of a movement, as opposed to a static one.

\subsection{Morphological Diversification and Objecthood}

The process of morphological diversification refers to the way that the program for a given building is broken into several building elements which are then given their own distinctive form. The idea of programmatic invention appears at this stage in Leonidov's project. It leads to correcting the given program of the building or adding new program to it, so as to generate new social ways of living with respect to the Soviet ideals. By doing so, Leonidov aimed to redefine the role of the architect as someone who elaborates the program, rather than as someone who simply interprets it.

In order to accentuate the contrasts between each programmatic element, Leonidov used repeatedly pure forms such as squares, circles and crosses in plan, as well as pyramids and spheres in volume. The use of such shapes is deeply influenced by the formal vocabulary of Kasimir Malevich's Suprematist paintings, which sought to reduce art to the expression of fundamental geometric forms.

The deliberate use of pure forms by Leonidov is radical in the sense that the architects of early modernism did not make use of them at that time. They would only become widespread decades later, exemplified by Buckminster Fuller's geodesic dome of 1967. The influence of industry, as a device solely devoted to the production of objects that can be manipulated in space, should also be regarded as a cause for the employment of such forms in Leonidov's work. The notion of objecthood is indeed strongly expressed in the way he used these forms, putting an emphasis not on the malleability of a single building in composition, but on the mobility of individual building components.

Their rational geometry also points to industrial manufacture, thus operating a synthesis of industrial design and architecture. From the outset of the Soviet Revolution, the radical rejection of the ornamented structures beloved by the bourgeoisie led to an expression of constructive elements only seen before in the architecture of factories. Early drawings by Iakov Chernikhov exemplify this rejection, and suggest a complete fusion between the appearance of the city and that of the factory. El Lissitsky provided clues to understand this mimetic phenomenon: "Under the state's master plan for building socialism, during the next five years the greater part of the budget will be devoted to industrialization. Accordingly, there can be no doubt that industrial architecture means more than merely providing a wrapping for a group of machines [8]". 
Pure forms have also been used by architects of the French Revolution such as Ledoux, Boullée and Durand, with a similar prominent use of the sphere, as a tool to express architectural autonomy, and abate the use of ornaments. The fact that Russian constructivists were aware of these experiments and even took their cue from them has been revealed. As Frampton pointed out, "despite the erotic and liberative dimensions suggested by this vision, Leonidov's architecture remains grounded in the paradigms of the eighteenth- and nineteenth-century avant-garde, that is to say, in pure geometry and pure technique as the arbiters of architectural form [9]”. However, these French Revolutionary projects remained essentially symmetrical and deeply rooted in the neoclassicism they aimed to counter. In opposition, it can be posited that the individuation and scattering of building elements proposed by Leonidov aimed to represent the process of radical re-organization of the political order of post-Revolutionary Russia.

\subsection{Compositional Sequence}

Following the proposed cinematic method of analysis, Fig. 2 displays the plans of Leonidov's major projects. From the similarities embedded in this set of plans, it is possible to deduce a general model to represent the compositional patterns at stake. Frampton noted that the projects that Leonidov produced after 1928 "were all, in effect, versions of his remarkable Lenin Institute projected a year earlier for a site in the Lenin Hills outside Moscow” [10].

Fig. 3 summarizes the stages observed in the recomposition stages of the projects. The first phase, as we have seen, concerns the program itself and its
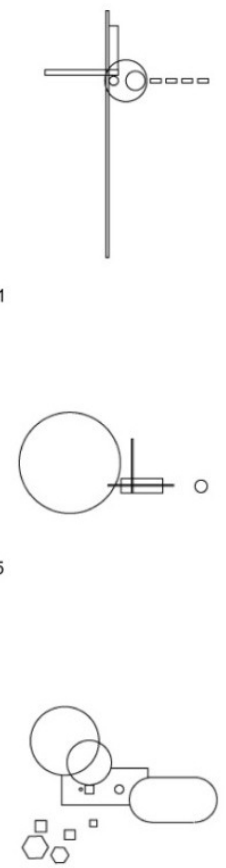
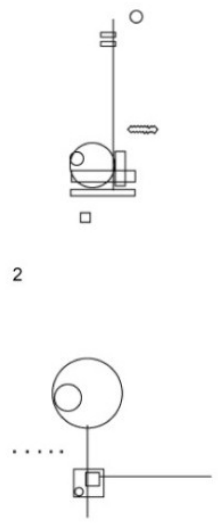

6

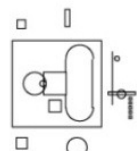

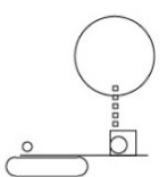
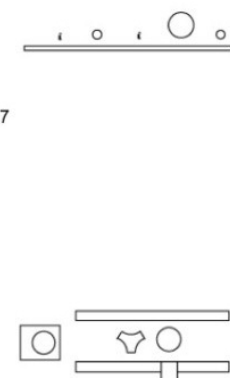
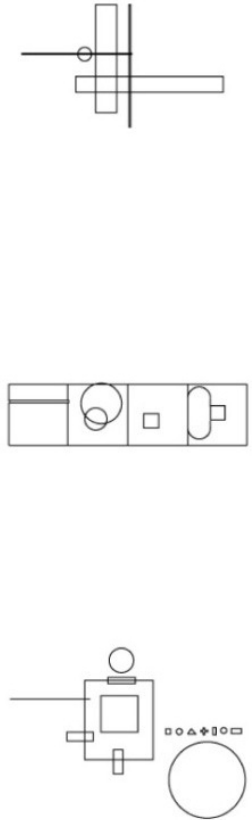

Fig. 2 Basic formal repertoire of Ivan Leonidov's architecture: 1-Lenin Institute, 1927; 2-Sov-Kino Film Production Complex, 1927; 3-A Club of a New Social Type, 1928; 4-Tsentrosoyouz Building, 1928; 5-House of Industry, 1929; 6-Monument to Christopher Columbus, 1929; 7-Magnitogorsk, Proposal for a New Town, 1930; 8-Palace of Culture, 1930; 9-Palace of Culture for the Proletarskii district of Moscow, 1930; 10-Square of Serpukhov, 1931; 11-Narkomtiazhprom, Commissariat of Heavy Industry, 1934; 12—The City of the Sun, 1943-1959. 


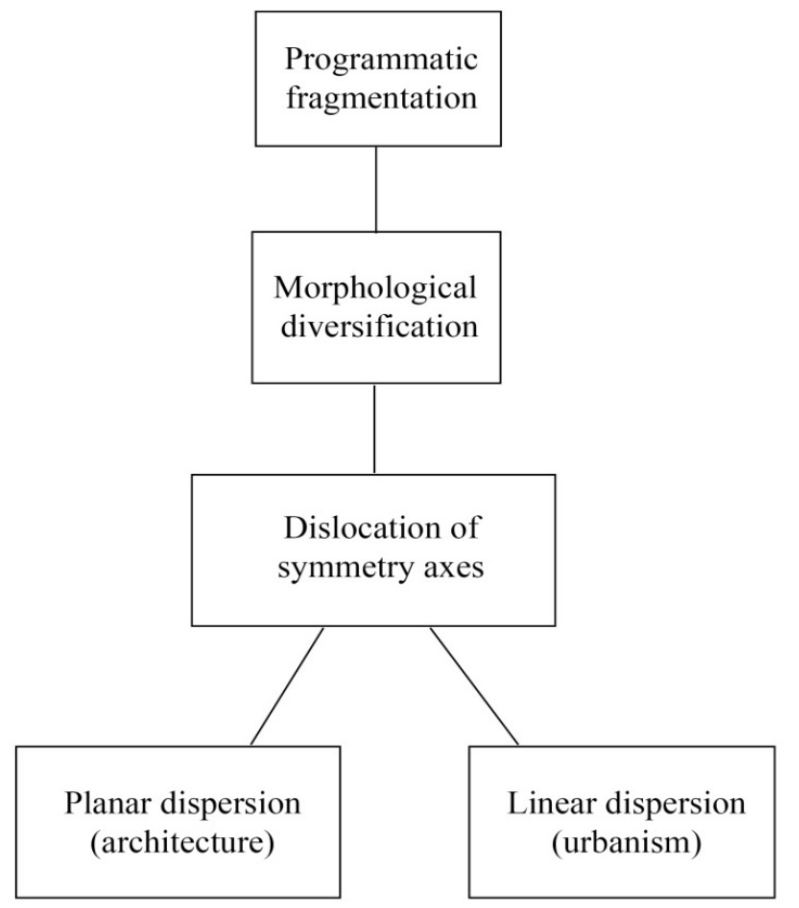

Fig. 3 General model of the compositional process of Ivan Leonidov's major projects.

breaking into several elements, which gives way to a diversity of forms that is emphasized by the use of simple shapes. It is at this stage that the idea of programmatic invention intervenes, adding unrequested program to the whole complex to generate improved social environments. Following these stages, the composition is operated by a dislocation of the main symmetry axes of the various forms that constitute the project, and by the translation of these forms along these axes. The result is a state of afocality for the entire composition, as the product of these movements lead to two possibilities: in architecture, it leads to a planar dispersion (or a radial dispersion that follows rectilinear paths), and in urbanism, to a linear dispersion, which can be clearly observed in Leonidov's project for the new town of Magnitogorsk.

Relating to this idea of space conquest is the notion of weightlessness, which can be felt as a general concept in Leonidov's compositions. In weightlessness, the respective centers of gravity of physical bodies follow straight trajectories and deny the notion of attraction to a common centre.
Leonidov's projects likewise require building elements to be clearly dissociated from each other, and their movement within the compositional field to be governed by straight lines, the only pattern of displacement of gravity centers in weightlessness. Supporting this hypothesis, Frampton asserted that: “at its most avant-garde, Leonidov's works project a supra-tectonic, an 'almost nothing' that attains its non-rhetorical apotheosis in its implied detachment from the earth [9]".

These projects have in fact to be reset in a historical context of yearning for outer space conquest, which utopian projects for flying cities by Russian architects such as Krutikov and Kalmykov clearly embody. These projects directly relate to the fact that the Soviet Union was originally meant to be a trans-national worker's state, free from nationalism. The concept of Russia as a separate national entity was in fact not emphasized in the early phase of the Soviet Union.

\section{Conclusions}

We have seen that in most of Leonidov's projects, 
once the main program has been fragmented, the various pieces of the program are then scattered on the given site. Although the elements of the projects are dislocated by sliding along their own set of orthogonal axes of symmetry, the effect of this measure is a radial dispersion of architectural space, if not the negation of the idea of the building as a whole.

The unique character of Leonidov's architecture can thus be seen as the combination of four general principles of composition: the use of heterogeneous pure forms in the same project, which use orthogonal vectors to dislocate themselves, an overall asymmetrical composition, and the principle of afocality. It should be stressed that none of these principles dominates the overall planning of the project, but that they work in connection with each other. Inherited from classical composition, pure forms and orthogonality express the idea of order, and in turn strengthen the expression of asymmetry and afocality, which generates the effect of disorder. In other words, Leonidov used pure forms and orthogonality specifically in order to emphasize the contrast with asymmetry and afocality, and therefore to accentuate the chaotic appearance of his compositions.

Afocality refers to the intentional absence of center in the planning of the project. This way of ordering the plan reminds of the plan of the acropolis, praised by Le Corbusier in "Towards a New Architecture", as a dynamic composition which, also, is asymmetrical in nature but whose various components are intrinsically symmetrical. Likewise, the idea of micro-urbanism, or in other words that of designing a building as a small city, or as a microcosm, can be seen as a recurring feature in many of Leonidov's projects, while avoiding the notion of center.

This particular projective methodology was congruent with the principles of decentralization and equitable redistribution of land, which the Soviet Union intended to enact in its early phase. Together with the idea of linear dispersion, or de-urbanism, it suggests a strong link to the construction of the USSR, a country with an extremely low density, and to the need to fill space with political presence at a crucial moment of the reorganization of the country as a whole. It is thus no surprise that nearly all the programs of Leonidov's early projects focused on the idea of dissemination of information through space.

Composition in classical and neoclassical architecture invariably opens toward the entrance of the main element of the project, so as to emphasize the notion of grandeur of the whole composition. Unsurprisingly, most totalitarian regimes have adopted the composition patterns of neoclassicism, and its penchant for unified axiality as a means to express the centralization of power, such as Ivan Fomin did in early post-Revolutionary Russia, and as Stalinism later forced Soviet architecture to return to. In opposition to these static compositional modes, Leonidov's work innovated in skilfully using the vocabulary of classicism in order to sharply contrast with its own rhetoric. By settling an idea of disorder in his compositions, and breaking with the rules of neoclassicism, he ascribed a specific political meaning to his projects, which can be seen as an attempt to dismantle the centralization of power in order to redefine social relationships through space.

\section{Reference}

[1] C. Cooke, Ivan Leonidov: Vision and historicism, Architectural Design 56 (6) (1986) 12-21.

[2] A.M. Vogt, Russian and French Revolutionary Architecture, Verlag M Dumont Schauberg, Cologne, 1974. (in German)

[3] S.O. Kahn-Magomedov, Pioneers of Soviet Architecture: The Search for New Solutions in the 1920s and 1930s, Thames and Hudson, London, 1987.

[4] A. Kopp, Town and Revolution: Soviet Architecture and City Planning, 1917-1935, New York, George Braziller, 1970.

[5] S.J. Summerson, The Classical Language of Architecture, MIT Press, Cambridge, 1966.

[6] L. Corbusier, Towards a New Architecture, Flammarion, Paris, 1995, p. 151. (in French) 
[7] A. Gozak, A. Leonidov, C. Cook, Ivan Leonidov: The Complete Works, Academy Editions, London, 1988, pp. 65-66.

[8] E. Lissitsky, Russia: The Reconstruction of Architecture in Soviet Union, Schroll \& Co., Vienna, 1929. (in

\section{German)}

[9] K. Frampton, Ivan Leonidov, Rizzoli, New York, 1981, p. 1.

[10] K. Frampton, Modern Architecture: A Critical History, Thames \& Hudson, London, 1980, p. 175. 